\title{
Parenting Adolescents in an Increasingly Diverse World: Links to Adolescents' Psychopathology
}

\author{
Inge Seiffge-Krenke \\ University of Mainz, Mainz, Germany \\ Email: seiffge-krenke@uni-mainz.de
}

How to cite this paper: Seiffge-Krenke, I. (2020). Parenting Adolescents in an Increasingly Diverse World: Links to Adolescents' Psychopathology. Psychology, 11, 874887.

https://doi.org/10.4236/psych.2020.116057

Received: April 18, 2020

Accepted: June 1, 2020

Published: June 4, 2020

Copyright $\odot 2020$ by author(s) and Scientific Research Publishing Inc. This work is licensed under the Creative Commons Attribution International License (CC BY 4.0).

http://creativecommons.org/licenses/by/4.0/

\begin{abstract}
Studies in Europe and North America have shown a strong impact of a negative parenting style (such as psychological control, separation anxiety and a lack of support) on adolescents' health. Western societies are increasingly becoming more ethnically diverse and we need more information about these links in the majority world. This overview focuses on the impact of cultural factors and parental rearing style on adolescent health including studies from all over the world. A universal finding was the strong impact of such negative parenting behaviour on depression, anxiety, and body complaints on boys and girls in diverse countries of the majority world. The impact was stronger for mothers' parenting than for fathers' and differed with respect to the gender of the child. Girls from step parent families and sons from mother-headed family were particularly sensitive to a negative parenting style. The universal findings call for joint prevention and interventions approaches.
\end{abstract}

\section{Keywords}

Parenting Style, Psychological Control, Psychopathology

\section{Introduction}

Families represent one of the most important developmental contexts for adolescents all over the world. There are marked, culturally-based differences in adolescents' family experiences and parental rearing styles (Georgas, Berry, van de Vijver, Kagitcibasi, \& Poortinga, 2006).

The negotiation of adolescent autonomy, a central developmental task for adolescents in Western industrialized countries, is not as critically important in 
Non-Western countries. However, most research has been conducted on immigrant families living in Western societies, which place higher values on individualism and egalitarianism in parent-adolescent relationships. Similarly, abundant research in Western countries has documented associations between negative parenting such as intrusive parenting tactics and controlling parental behaviour and adolescent psychopathology. Despite the fact that over $90 \%$ of young people live in the "majority world" (a term used as alternative to "developing countries"), the research on parenting and psychopathology of the offspring did not capture parent-adolescent relationships from other countries than the US or European countries (e.g. the "minority world").

In this article, we will provide essential research findings on the links between parenting and adolescents' psychopathology in countries of the majority world. As a starting point, we will outline findings on adolescents raised by immigrant families. Second, we consider research on adolescent psychopathology from a cross-cultural perspective. Third, we integrate both perspectives and present research on parenting and adolescents' psychopathology in diverse countries from the majority world. We focus on internalizing symptoms (such as depression and anxiety) and on externalizing symptoms (such as antisocial behaviour and delinquency). In addition, we analyse which cultural factors and parental rearing styles contribute to the expression of psychological distress via body complaints. We suppose that the open expression of distress by symptoms such as depression or antisocial behaviour is not seen as adequate in every countries and that in some cultures, cultural script prescribe amore hidden expression in the form of bodily symptoms. Finally, we discuss some consequences for research and health policy.

\section{Parenting Adolescents in an Increasingly Diverse World}

Demographic trends reveal increasing diversity within and between families in many countries. US families are increasingly multicultural, with EuropeanAmerican families constituting only half (65\%) of families, and Asian American families replacing Latin Americans as the fastest growing US immigrant group (Hussong \& Jones, 2018). Many of these families are suffering from economic hardship (UNICEF, 2014). Moreover, families are themselves increasingly racially and ethnically diverse, with a strong increase in intermarriages in recent years. The increasing rates of immigrant families and high rates of intermarriage have been reported also from European countries, where the rate of intermarriages has tripled in recent years. Such diversity represents a shift in the sociopolitical context navigating by todays' adolescents and their families, challenging how we define the construct of family and the process of parenting.

In American and European studies, this diversity has been taken into account in recent years and many studies have been done comparing different ethnicities within one country in their parenting (see, for example, Fuligni, Tseng, \& Lam, 1999; Kunz \& Hanvey, 2000; Masten \& Wright, 2010). They demonstrate that 
within a country, parenting differs enormously, depending on cultural script on what is considered the "right" parenting, different socio-economic backgrounds and different concepts of what function autonomy has in this process. Most of these adolescents construct a bicultural identity (Arnett, 2008).

\section{Parenting an Adolescent and the Window of Vulnerability}

Adolescence is a time of change where adolescents have to cope with many developmental challenges. They have to address normative developmental tasks such as reconceptualization of their identity, forming a mature body concept, and investing in extrafamiliar relationships, all of which can be related to an increase of mental health symptoms during this developmental period (Klimstra \& Denissen, 2017) with long-term implications for the health during emerging adulthood. In addition, parent-adolescent relationships undergo a transformation towards increasing autonomy and independence (Laursen \& Collins, 2009), resulting in higher levels of parent-adolescent conflicts during mid-adolescence (Van Doorn, Branje, \& Meeus, 2011). Level of stress and of parent-adolescent conflicts are not only linked to current higher symptomatology (Persike \& Seiffge-Krenke, 2016), but impacts health in emerging adulthood (Salafia \& Gondoli, 2011). Taken together, the adolescent period is as a window of vulnerability for developing psychopathology during this developmental phase but has, additionally, a long-term impact on future health. The way parents deal with the adolescents' increasing need for autonomy contributes substantially to their offspring's health. The negotiation of adolescent autonomy, a central developmental task for adolescents in Western industrialized countries, is not as critically important in other countries. As well, the importance assigned to adolescent peer culture in European and North American countries may not be paralleled in the majority world (Brown, Larson, \& Saraswathi, 2002). Further, the way parents support or control their children may differ across different cultures (McNeely \& Barber, 2010).

While parenting across cultures may take on different forms and functions during adolescence, it is essential to understand how various dimensions of parenting promote adolescents' health and well-being in a cross-cultural context. From a cultural psychopathology perspective (Ryder, Yang, \& Heine, 2002), it seems sensible and necessary to explore different indicator of adolescent health and well-being and to analyze their associations with family relations and culture.

\section{Parent-Child Relationships and Adolescent Psychopathology; Findings from Western Countries}

Recent research has identified a number of parenting dimensions that are related to adolescent psychopathology. Mainly two fundamental components of parenting are put forward: 1) a supportive component, defined by an assortment of affective, nurturant, or companionate types of parental behavior, and 2) a con- 
trolling component, defined by a range of regulating, disciplinary behaviors, which, in some frameworks, has been further organized by "whether or not the regulation is exercised with sensitivity or responsiveness to the self or autonomy of the child being controlled" (Barber, Stolz, \& Olsen, 2005b: p. 2). Of note, psychological and behavioural control are not describing too much and too little control, instead, they are two qualitatively different dimensions. Psychologically controlling parents lack the empathic capacities necessary to properly respond to their adolescent's physical, emotional, and psychological needs (Barber, Stolz, Olsen, Collins, \& Burchinal, 2005a). This intrusive parenting is thought to be especially harmful during adolescence, as it often interferes with the adolescent's autonomy development, contributing to greater dependence on parents and social isolation (Barber \& Xia, 2013; Soenens, Vansteenkiste, \& Luyten, 2010; Soenens et al., 2012). Besides limiting the child's autonomy, it is the feeling of being disrespected what leads to the negative health outcomes of psychological control (Barber et al., 2012). In studies with varying methodologies, psychological control was consistently related to internalizing problems and sometimes with externalizing problems, as well as with conflicts with parents, and adjustment difficulty (Barber et al., 2005c).

More recently, anxious child rearing practices, partly caused by parents' separation anxiety, has come into the focus: a tendency to provide (too much) protection (Bradley-Geist \& Olson-Buchanan, 2014; Kins et al., 2011). Such hovering parental behaviour has been found in samples in central Europe and in North America (Kins et al., 2013; LeMoyne \& Buchanan, 2011; Segrin, Givertz, Swaitkowski, \& Montgomery, 2015). Padilla-Walker \& Nelson (2012) are proposing that this so called "helicopter parenting" is not an entirely new dimension of parenting. Instead, it represents parenting that is high on warmth/support, high on control, and low on granting autonomy.

In a meta-analysis on the relation of parenting and child anxiety, anxiety was associated with autonomy-granting and overinvolvement, and to a lesser degree with withdrawal and aversiveness (McLeod et al., 2007). Parent's gender was no significant moderator in the analysis. In this meta-analyses, only three of 47 studies reported having assessed a predominantly non-Caucasian sample (African American, Asian, and Latino).

A meta-analysis on predictors of delinquency reported that the strongest links were found for parental monitoring, psychological control, and negative aspects of support such as rejection and hostility, accounting for up to $11 \%$ of the variance (Hoeve et al., 2009).

Parental support may serve as a buffer to enable a healthy development (Bilsky et al., 2013; Hazel et al., 2014; Lösel \& Farrington, 2012). Consequently, low levels of parental behaviour control have been consistently linked to higher externalizing problem behaviours (Barber, Stolz, Olsen et al., 2005b; Hoeve et al., 2009). In a meta-analysis including 45 studies looking at the association of parenting and child depression, parenting accounted for $8 \%$ of the variance with 
parental rejection (in particular parental hostility) being more strongly related to depression than parental control (5\%) (McLeod et al., 2007). Of the 45 studies, only one had a predominantly Latino sample and further five an Asian sample, the rest of the studies were based in Western countries.

\section{The Impact of Negative Parenting Practices on Adolescent Internalizing and Externalizing Symptoms across Different Cultures}

Research in cultural psychopathology (Ryder, Yang, \& Heine, 2002; Rescorla et al., 2007a) has demonstrated that cultural factors play a role in explaining the high variation in experience and expression of psychological distress and theories of parenting espouse the importance of situating parenting within a broader cultural context (e.g. Bornstein, 2012). Although there are studies comparing two countries and report, for example, that Chinese parents are more psychologically controlling than American parents (Ng, Pomerantz, \& Deng, 2014), there have been few empirical studies to examine the links to health and test whether the associations between parental behaviours and adolescents' psychopathology appear similarly in diverse international contexts.

When analyzing adolescent mental disorders, the magnitude of the problem across the globe became apparent. Studies investigating behavioral and emotional problems reported by parents of children aged 6 to 16 in 31 societies reported enormous variations in externalizing and internalizing symptoms with low rates in Japan and Sweden and high rates in Puerto Rico and Etiopia (Ivanova et al., 2015; Rescorla et al., 2007b). The findings indicate that parents' report of adolescent symptomatology were similar in many ways across highly diverse countries. Nonetheless, effect sizes for country were larger than for age and gender of the child.

Similarly, in a cross-cultural studies on adolescents from eight countries (Argentina, Germany, France, Pakistan, Peru, Greece, Poland and Turkey), Weitkamp \& Seiffge-Krenke (2018) found a significant impact of culture when predicting adolescents' symptomatology. Adolescents from Pakistan and Peru reported comparably high levels and adolescents from Greece and Turkey reported comparably low levels in internalizing symptoms with France, Germany, and Poland reporting medium levels in internalizing symptomatology. Adolescents from Germany reported the highest levels of externalizing symptoms, compared to adolescents from other countries. These findings account for varying life situations for adolescents in different cultures. In addition, culturally dependent reporting styles or varying experience or expression of mental health symptoms may have a bearing (Hughes et al. 2006). Further, in the study of Weitkamp \& Seiffge-Krenke (2018), a very different impact of mothers' and fathers' rearing style on internalizing and externalizing symptoms of the offspring was found. Parental anxious rearing and psychological control was rated as relatively high in some countries like Peru and Argentina and, to a lesser degree, in Germany, 
Poland or Greece. In all eight countries, the effect of mothers anxious rearing and psychological control was associated with internalizing symptoms; the impact was less uniform with respect to fathers' anxious rearing. Overall, parents' psychological control had a more negative impact than parents anxious rearing. Further, although parents' supportive behavior was perceived quite different across countries, and seemed higher for mothers than fathers, mothers support had no impact, when predicting adolescents' internalizing symptomatology. However, fathers' supportive behavior served as a buffer in contributing to lower levels of externalizing symptoms, a finding noted also in research on delinquency (Hagan \& Foster, 2003).

Earlier studies also found culture-specific differences in parenting with higher levels of parental control in Arab countries, and consequently, an impaired health of the offspring (Al-Eissa et al., 2016) with higher rates in depression and anxiety (Ijaz \& Mahmood, 2009). Higher levels of psychological control were established in families of Mexican and Asian youth than in families with adolescents from the US (Barber et al., 2005c; NG et al., 2014; Sher-Censor et al., 2011). Conflicting pressures of Korean parents on adolescents to achieve in school and to fulfill family obligations have resulted in higher symptomatology in their children (Chang 2013). In contrast to this, support by parents build up resiliency and reduce psychopathology, for example in adolescents from Uganda (Haroz et al., 2013), Korea (Chan, 2013) and Latin America (Welti, 2002).

\section{The Impact of Negative Parenting Practices on Adolescents' Body Complaints across Different Cultures}

Although cultural dimensions have been applied in mental health research with a focus on open expression of psychological symptoms (Hodges \& Oei, 2007; Hoebert et al., 2017; Johnson, 2007; Sheikh \& Furnham, 2009), much less is known about the more hidden expression of distress via body symptoms.To date, not many studies have investigated whether such difficult parenting practices may contribute to the high rate of body complaints seen in adolescents around the globe. Several studies in different countries revealed quite high rates of body complaints in non-clinical adolescent samples, for example in the German-wide representative Hamburg Health Survey (Barkmann et al., 2011), the Great Smoky Mountains Study in the US (Link Egger et al., 1999), and large studies on school-based populations in Sweden (Alricsson, Landstad, Romild, \& Werner, 2006), in Israel (Genizi, Srugo, \& Kerem, 2013), in China (Zaroff et al., 2012), and in Pakistan (Rehna, Hanif, Laila, \& Ali, 2016). In these studies, the prevalence rates ranged between $31 \%$ and $64 \%$ during the last three months, with higher rates in girls compared to boys.

In the context of psychological distress, it is suggested that members of non-Western cultures are more likely to report bodily symptoms rather than purely affective ones (Ma-Kellams, 2014). In some cultures, for example the Chinese culture, due to severe social stigma attached to mental health problems, 
the somatic expression of psychological distress is more acceptable than the expression of anxiety or depression and also elicits far greater social support (Hoebert, Mantel-Teeuwisse, Leufkens, \& Van Dijk, 2017). The concept of "Western psychologisation" has been suggested to counterpart "Asian somatization".

Hofstede's model of cultural dimensions distinguished six dimensions along which cultural values can be compared with other cultures: individualism vs. collectivism, power distance, indulgence vs. restraint, masculinity vs. femininity, uncertainty, and long-term orientation vs. short-term orientation (Hofstede, 2011; Hofstede, 2015). Where European/Western cultures place more emphasis on individualistic goals and value independence, more collectivistic cultures, like Middle East and South American cultures, place more emphasis on interdependence. Individual behaviour is guided more by mutual obligations, and strive to maintain harmonious relationships with others (Kemmelmeier et al., 2003; Oyserman, Coon, \& Kemmelmeier, 2002). In Latino families, it is important to raise a child that is "bien educato", showing respect and obedience for the purpose of harmony (Tamis-LeMonda et al., 2008). Cultures vary in the way that it is accepted that power is distributed unequally (Hofstede, 2011). In cultures scoring particularly high or low on this dimension, young people might experience controlling parenting behaviours quite differently. Feminine societies place greater emphasis on cooperation and quality of life considerations and de-emphasize competition and personal success (Johnson, 2007).

When classifying eight countries involved (Argentina, France, Germany, Greece, Pakistan, Peru, Poland, and Turkey) according to the six dimensions based on Hofstede (2015), Seiffge-Krenke et al. (2020) found substantial variation between the countries in each of the six dimensions, with higher variation in individualism, but less variation in power distance and masculinity. Although the level of body complaints was higher in girls than in boys, the association with cultural dimensions was quite similar for both genders. Cultural dimensions played an even greater role for boys in explaining variance than in girls, confirming results from studies in India (Rao et al., 2013).

In cultures with a higher pressure on an individual level to achieve, for example in Germany, more somatic complaints were reported, whereas in cultures that value indulgence (Turkey, Greece, and Argentina), less somatic symptoms were reported (Seiffge-Krenke et al., 2020). In cultures under acute external stress, youth reported very high body complaints, this was demonstrated for youth in Pakistan.

Across all eight countries, for boys, coming from a single parent family and having a working mother was associated with higher rates of body complaints (Seiffge-Krenke et al., 2020). Possibly, a son in a mother-headed family, especially when the mother is working, is more hesitant in openly expression discomfort, loneliness, or conflicts and thus expresses his distress by body complaints, which, possibly, also have a function in getting support and care by his 
working mothers (see for example Hoebert et al., 2017). In contrast, living in a stepfamily was associated with higher body complaints in girls in all eight countries (Seiffge-Krenke et al., 2020). It seems that daughters feel uncomfortable, but do not dare to share openly, but instead "speak with their bodies". Possibly, females stronger emotional control in step-father family may play a role (Sun \& Lau, 2018).

Although cultural factors served as the strongest predictor of body complaints in adolescents from all eight countries, negative parenting served as second strong predictor Parental psychological control (for boys) and intrusive and monitoring behaviour by mothers (for girls) was perceived as distressing and linked with higher rates of somatic complaints. By contrast, father's anxious monitoring was experienced as positive by daughters, resulting in fewer body symptoms, a finding pointing to the different roles, fathers and mothers play during adolescence (Cassano et al., 2006).

\section{Conclusion}

The role of negative parenting practices on adolescents' health, like a lack of support and high rates of parental psychological control, has been examined with a focus on parenting in Western industrialized countries. While enormous variations in externalizing and internalizing symptoms and body complaints were found in adolescents around the globe, much less is known about the cultural impact e.g. the contribution cultural factors make up and above perceived parental behavior. This overview therefore analysed the ways in which cultural factors and parental rearing styles contribute to the expression of psychological distress (internalizing and externalizing symptoms and body complaints) in adolescents from different countries around the world.

Despite varying rates of various parenting style across different cultures, a negative impact of anxious rearing and too much psychological and behavioural control on the child's physical or mental health was found. Universal was also the detrimental effect of a lack of parental support. Further, the impact of mothers' and fathers' rearing style for sons and daughters health differed.Together, findings show a cultural generalizability: In most countries, psychological control as a parenting style was associated with the highest rates of psychological and physical complaints. This finding calls for joint prevention and intervention in diverse countries.

Future studies should investigate bidirectional influences, e.g. consider the possibility that high levels of symptoms in the offspring may result in more control both behaviorally and psychologically, in parents (see, for example, Lansford et al., 2018). We need more research, as the explanations for cultural differences in psychological symptoms and body complaints are complex, including linguistic features of the language, stigma associated with psychiatric conditions (Dreher et al., 2017) or differences in emotional expression norms (Ma-Kellams, 2014), Also we have to consider a different exposure to severe traumatic events 
for those living in unsafe environments (Garnefski, van Rood, de Roos, \& Kraaij, 2017). An increasing globalization leads to more similarity in parenting and symptom expression in middle class families, but there are still families living in the margins and growing up in extreme poverty. Future studies should therefore analyze the links between parenting and psychopathology in vulnerable populations in different countries.

\section{Conflicts of Interest}

The author declares no conflicts of interest regarding the publication of this paper.

\section{References}

Al-Eissa, M. A., Saleheen, H. N., AlMadani, S., AlBuhairan, F. S., Weber, A., Fluke, J. D., Casillas, K. L. et al. (2016). Determining Prevalence of Maltreatment among Children in the Kingdom of Saudi Arabia. Child: Care, Health and Development, 42, 565-571. https://doi.org/10.1111/cch.12325

Alricsson, M., Landstad, B. J., Romild, U., \& Werner, S. (2006). Self-Related Health, Physical Activity and Complaints in Swedish High School Students. The Scientific World Journal, 6, 816-826. https://doi.org/10.1100/tsw.2006.164

Arnett, J. J. (2008). The Neglected 95\%. Why American Psychology Needs to Become Less American. American Psychologist, 63, 602-614. https://doi.org/10.1037/0003-066X.63.7.602

Barber, B. K., \& Xia, M. (2013). The Centrality of Control to Parenting and Its Effects. In R. E. Larzelere, A. Sheffield Morris, \& A. W. Harrist (Eds.), Authoritative Parenting: Synthesizing Nurturance and Discipline for Optimal Child Development (pp. 61-87). Washington DC: American Psychological Association. https://doi.org/10.1037/13948-004

Barber, B. K., Stolz, H. E. E., Olsen, J. A. A., Collins, A., \& Burchinal, M. (2005a). Parental Support, Psychological Control, and Behavioral Control: Assessing Relevance across Time, Method, and Culture. Monographs of the Society for Research in Child Development, 70, 1-137.

Barber, B. K., Stolz, H. E., \& Olsen, J. A. (2005b). Parental Support, Psychological Control, and Behavioral Control: Assessing Relevance across Time, Culture, and Method. Monographs of the Society for Research in Child Development, 70, 1-137.

Barber, B. K., Stolz, H. E., Olsen, J. A., Collins, A., \& Burchinal, M. (2005c). Assessing Relevance across Culture: Cross-National Replications. Monographs of the Society for Research in Child Development, 70, 58-72. https://doi.org/10.1111/j.1540-5834.2005.00369.x

Barber, B. K., Xia, M., Olsen, J. A., McNeely, C. A., \& Bose, K. (2012). Feeling Disrespected by Parents: Refining the Measurement and Understanding of Psychological Control. Journal of Adolescence, 35, 273-287. https://doi.org/10.1016/j.adolescence.2011.10.010

Barkmann, C., Braehler, E., Schulte-Markwort, M., \& Richterich, A. (2011). Chronic Somatic Complaints in Adolescents: Prevalence, Predictive Validity of the Parent Reports, and Associations with Social Class, Health Status, and Psychosocial Distress. Social Psychiatry and Psychiatric Epidemiology, 46, 1003-1011.

https://doi.org/10.1007/s00127-010-0273-4 
Bilsky, S. A., Cole, D. A., Dukewich, T. L., Martin, N. C., Sinclair, K. R., Tran, C. V. et al. (2013). Does Supportive Parenting Mitigate the Longitudinal Effects of Peer Victimization on Depressive Thoughts and Symptoms in Children? Journal of Abnormal Psychology, 122, 406-419. https://doi.org/10.1037/a0032501

Bornstein, M. (2012). Cultural Approaches to Parenting. Parenting: Science and Practices, 12, 212-221. https://doi.org/10.1080/15295192.2012.683359

Bradley-Geist, J. C., \& Olson-Buchanan, J. B. (2014). Helicopter Parents: An Examination of the Correlates of Over-Parenting of College Students. Education + Training, 56, 314-328. https://doi.org/10.1108/ET-10-2012-0096

Brown, B. B., Larson, R., \& Saraswathi, T. S. (2002). The World's Youth: Adolescents in Eight Regions of the Globe. Cambridge: Cambridge University Press.

https://doi.org/10.1017/CBO9780511613814

Cassano, M., Adrian, M., Veits, G., \& Zeman, J. (2006). The Inclusion of Fathers in the Empirical Investigation of Child Psychopathology: An Update. Journal of Clinical Child \& Adolescent Psychology, 35, 583-589. https://doi.org/10.1207/s15374424jccp3504_10

Chan, E. S. (2013). Negotiating Family Obligations and Educational Goals among College-Enrolled Youth on Jeju Island, Korea. Journal of Research on Adolescence, 33, 25-34. https://doi.org/10.1111/j.1532-7795.2012.00814.x

Dreher, A., Hahn, E., Diefenbacher, A., Nguyen, M. H., Böge, K., Burian, H., Ta, T. M. T. et al. (2017). Cultural Differences in Symptom Representation for Depression and Somatization Measured by the PHQ between Vietnamese and German Psychiatric Outpatients. Journal of Psychosomatic Research, 102, 71-77. https://doi.org/10.1016/j.jpsychores.2017.09.010

Fuligni, A. F., Tseng, V., \& Lam, M. (1999). Attitudes towards Family Obligations among American Adolescents with Asian, Latin American, and European Backgrounds. Child Development, 70, 1030-1044. https://doi.org/10.1111/1467-8624.00075

Garnefski, N., van Rood, Y., de Roos, C., \& Kraaij, V. (2017). Relationships between Traumatic Life Events, Cognitive Emotion Regulation Strategies, and Somatic Complaints. Journal of Clinical Psychology in Medical Settings, 24, 144-151. https://doi.org/10.1007/s10880-017-9494-y

Genizi, J., Srugo, I., \& Kerem, N. C. (2013). The Cross-Ethnic Variations in the Prevalence of Headache and Other Somatic Complaints among Adolescents in Northern Israel. The Journal of Headache and Pain, 14, 21.

https://doi.org/10.1186/1129-2377-14-21

Georgas, J., Berry, J. W., Vijver, F. J. R. van de, Kagitçibasi, Ç., \& Poortinga, Y. H. (2006). Families across Cultures: A 30-Nation Psychological Study. Cambridge: Cambridge University Press. https://doi.org/10.1017/CBO9780511489822

Hagan, J., \& Foster, H. (2003). S/He's a Rebel: Toward a Sequential Stress Theory of Delinquency and Gendered Pathways to Disadvantage in Emerging Adulthood. Social Forces, 82, 53-86. https://doi.org/10.1353/sof.2003.0091

Haroz, E. E., Murray, L. K., Boltob, P., Belancourt, T., \& Bass, J. A. (2013). Adolescent Resilience in Northern Uganda: The Role of Social Support and Prosocial Behavior in Reducing Mental Health Problems. Journal of Research on Adolescence, 23, 138-148. https://doi.org/10.1111/j.1532-7795.2012.00802.x

Hazel, N., Oppenheimer, C., Technow, J., Young, J., \& Hankin, B. (2014). Parent Relationship Quality Buffers against the Effect on Depressive Symptoms from Middle Childhood to Adolescence. Developmental Psychology, 50, 2115-2123.

https://doi.org/10.1037/a0037192 
Hodges, J., \& Oei, T. P. S. (2007). Would Confucius Benefit from Psychotherapy? The Compatibility of Cognitive Behaviour Therapy and Chinese Values. Behaviour Research and Therapy, 45, 901-914. https://doi.org/10.1016/j.brat.2006.08.015

Hoebert, J. M., Mantel-Teeuwisse, A. K., Leufkens, H. G. M., \& Van Dijk, L. (2017). Variability in Market Uptake of Psychotropic Medications in Europe Reflects Cultural Diversity. BMC Health Services Research, 17, 1-9. https://doi.org/10.1186/s12913-017-2649-6

Hoeve, M., Dubas, J. S., Eichelsheim, V. I., van der Laan, P. H., Smeenk, W., \& Gerris, J. R. M. (2009). The Relationship between Parenting and Delinquency: A Meta-Analysis. Journal of Abnormal Child Psychology, 37, 749-775. https://doi.org/10.1007/s10802-009-9310-8

Hofstede, G. H. (2011). Dimensionalizing Cultures: The Hofstede Model in Context. Online Readings in Psychology and Culture, 2, 1-26.

https://doi.org/10.9707/2307-0919.1014

Hofstede, G. H. (2015). Dimension Data Matrix. https://geerthofstede.com/research-and-vsm/dimension-data-matrix

Hughes, D., Rodriguez, J., Smith, E. P., Johnson, D. J., Stevenson, H. C., \& Spicer, P. (2006). Parents' Ethnic-Racial Socialization Practices: A Review of Research and Directions for Future Study. Developmental Psychology, 42, 747-770. https://doi.org/10.1037/0012-1649.42.5.747

Hussong, A. M., \& Jones, D. J. (2018). Parenting Adolescents in an Increasingly Diverse World: Defining, Refining, and Extending Theory and Research. Journal of Research on Adolescence, 28, 568-570. https://doi.org/10.1111/jora.12398

Ijaz, T., \& Mahmood, Z. (2009). Relationship between Perceived Parenting Styles and Levels of Depression, Anxiety, and Frustration Tolerance in Female Students. Pakistan Journal of Psychological Research, 24, 63-78.

Ivanova, M. Y., Achenbach, T. M., Rescorla, L., Turner, L. V., Ahmeti-Pronaj, A., Au, A., Zasepa, E. et al. (2015). Syndromes of Self-Reported Psychopathology for Ages 18-59 in 29 Societies. Journal of Psychopathology and Behavioral Assessment, 37, 171-183. https://doi.org/10.1007/s10862-014-9448-8

Johnson, T. P. (2007). Cultural-Level Influences on Substance Use \& Misuse. Substance Use and Misuse, 42, 305-316. https://doi.org/10.1080/10826080601142022

Kemmelmeier, M., Burnstein, E., Krumov, K., Genkova, P., Kanagawa, C., Hirshberg, M. S., Noels, K. A. et al. (2003). Individualism, Collectivism, and Authoritarianism in Seven Societies. Journal of Cross-Cultural Psychology, 34, 304-322. https://doi.org/10.1177/0022022103034003005

Kins, E., Soenens, B., \& Beyers, W. (2011). "Why Do They Have to Grow Up So Fast?" Parental Separation Anxiety and Emerging Adults' Pathology of Separation-Individuation. Journal of Clinical Psychology, 67, 647-664. https://doi.org/10.1002/jclp.20786

Kins, E., Soenens, B., \& Beyers, W. (2013). Separation Anxiety in Families with Emerging Adults. Journal of Family Psychology, 27, 495-505. https://doi.org/10.1037/a0032869

Klimstra, T. A., \& Denissen, J. J. A. (2017). A Theoretical Framework for the Associations between Identity and Psychopathology. Developmental Psychology, 53, 2052-2065. https://doi.org/10.1037/dev0000356

Kunz, J., \& Harvey, L. (2000). Immigrant Youth in Canada. Ottawa: Renouf Books.

Lansford, J., Rothenberg, W. A., Jensen, T., Lippold, M., Bacchini, E., Bornstein, M. H., Al-Hassan, S. M. et al. (2018). Bidirectional Relations between Parenting and Behavior Problems from Age 8 to 13 in Nine Countries. Journal of Research on Adolescence, 28, 
571-590. https://doi.org/10.1111/jora.12381

Laursen, B., \& Collins, J. K. (2009). Parent-Child Relationships during Adolescence. In R. M. Lerner, \& L. Steinberg (Eds.), Handbook of Adolescent Psychology, Vol. 2 (pp. 3-42). Hoboken, NJ: John Wiley \& Sons. https://doi.org/10.1002/9780470479193.adlpsy002002

LeMoyne, T., \& Buchanan, T. (2011). Does "Hovering" Matter? Helicopter Parenting and Its Effect on Well-Being. Sociological Spectrum, 31, 399-418. https://doi.org/10.1080/02732173.2011.574038

Link Egger, H., Costello, E. J., Erkanli, A., \& Angold, A. (1999). Somatic Complaints and Psychopathology in Children and Adolescents: Stomach Aches, Musculoskeletal Pains, and Headaches. Journal of the American Academy of Child and Adolescent Psychiatry, 38, 852-860. https://doi.org/10.1097/00004583-199907000-00015

Lösel, F., \& Farrington, D. P. (2012). Direct Protective and Buffering Protective Factors in the Development of Youth Violence. American Journal of Preventive Medicine, 43, S8-S23. https://doi.org/10.1016/j.amepre.2012.04.029

Ma-Kellams, C. (2014). Cross-Cultural Differences in Somatic Awareness and Interoceptive Accuracy: A Review of the Literature and Directions for Future Research. Frontiers in Psychology, 5, 1-9. https://doi.org/10.3389/fpsyg.2014.01379

Masten, A. S., \& Wright, M. O. (2010). Resilience over the Life Span. In J. W. Reich (Ed.), Handbook on Adult Resilience (pp. 213-237). New York: Guilford Press.

McLeod, B. D., Weisz, J. R., \& Wood, J. J. (2007). Examining the Association between Parenting and Childhood Depression: A Meta-Analysis. Clinical Psychology Review, 27, 986-1003. https://doi.org/10.1016/j.cpr.2007.03.001

McNeely, C. A., \& Barber, B. K. (2010). How Do Parents Make Adolescents Feel Loved? Perspectives on Supportive Parenting from Adolescents in 12 Cultures. Journal of Adolescent Research, 25, 601-631. https://doi.org/10.1177/0743558409357235

Ng, F. F., Pomerantz, E. M., \& Deng, C. (2014). Why Are Chinese Parents More Psychologically Controlling than American Parents? Child Development, 85, 355-369. https://doi.org/10.1111/cdev.12102

Oyserman, D., Coon, H. M., \& Kemmelmeier, M. (2002). Rethinking Individualism and Collectivism: Evaluation of Theoretical Assumptions and Meta-Analyses. Psychological Bulletin, 128, 3-52. https://doi.org/10.1037/0033-2909.128.1.3

Padilla-Walker, L. M., \& Nelson, L. J. (2012). Black Hawk Down? Establishing Helicopter Parenting as a Distinct Construct from Other Forms of Parental Control during Emerging Adulthood. Journal of Adolescence, 35, 1177-1190. https://doi.org/10.1016/j.adolescence.2012.03.007

Persike, M., \& Seiffge-Krenke, I. (2016). Stress with Parents and Peers: How Adolescents from 18 Nations Cope with Relationship Stress. Anxiety, Stress, \& Coping, 29, 38-59. https://doi.org/10.1080/10615806.2015.1021249

Rao, M. A., Berry, R., Gonsales, A., Hastak, Y., Sha, M., \& Roeser, R. W. (2013). Globalization and the Identity Remix among Urban Adolescents in India. Journal of Research on Adolescence, 33, 9-24. https://doi.org/10.1111/jora.12002

Rehna, T., Hanif, R., Laila, U., \& Ali, S. Z. (2016). Life Stress and Somatic Symptoms among Adolescents: Gender as Moderator. Journal of Pakistan Medical Association, $66,1448-1451$.

Rescorla, L., Achenbach, T. M., Ivanova, M. Y., Dumenci, L., Almqvist, F., Bilenberg, N., Verhulst, F. et al. (2007a). Epidemiological Comparisons of Problems and Positive Qualities Reported by Adolescents in 24 Countries. Journal of Consulting and Clinical 
Psychology, 75, 351-358. https://doi.org/10.1037/0022-006X.75.2.351

Rescorla, L., Achenbach, T., Ivanova, M. Y., Dumenci, L., Almqvist, F., Bilenberg, N., Bird, H., Wei, C. et al. (2007b). Behavioral and Emotional Problems Reported by Parents of Children Ages 6 to 16 in 31 Societies. Journal of Emotional and Behavioral Disorders, 15, 130-142. https://doi.org/10.1177/10634266070150030101

Ryder, A. G., Yang, J., \& Heine, S. J. (2002). Somatization vs. Psychologization of Emotional Distress: A Paradigmatic Example for Cultural Psychopathology. Online Readings in Psychology and Culture, 10, 1-22. https://doi.org/10.9707/2307-0919.1080

Salafia, E. H. B., \& Gondoli, D. M. (2011). A 4-Year Longitudinal Investigation of the Processes by Which Parents and Peers Influence the Development of Early Adolescent Girls' Bulimic Symptoms. Journal of Early Adolescence, 31, 390-414. https://doi.org/10.1177/0272431610366248

Segrin, C., Givertz, M., Swaitkowski, P., \& Montgomery, N. (2015). Overparenting Is Associated with Child Problems and a Critical Family Environment. Journal of Child and Family Studies, 24, 470-479. https://doi.org/10.1007/s10826-013-9858-3

Seiffge-Krenke, I., Sattel, H., Cavdar, D. \& Öncü, B. (2020). Parental Rearing Styles and Cultural Dimensions as Predictors of Adolescents' Somatic Complaints: A Cross-Cultural Study in Eight Countries. Child and Adolescent Psychiatry. (In Press)

Sheikh, S., \& Furnham, A. (2009). A Cross-Cultural Study of Mental Health Beliefs and Attitudes towards Seeking Professional Help. Community Mental Health Journal, 45, 26-36. https://doi.org/10.1007/s10597-008-9175-2

Soenens, B., Park, S. Y., Vansteenkiste, M., \& Mouratidis, A. (2012). Perceived Parental Psychological Control and Adolescent Depressive Experiences: A Cross-Cultural Study with Belgian and South-Korean Adolescents. Journal of Adolescence, 35, 261-272. https://doi.org/10.1016/j.adolescence.2011.05.001

Soenens, B., Vansteenkiste, M., \& Luyten, P. (2010). Toward a Domain-Specific Approach to the Study of Parental Psychological Control: Distinguishing between Dependency-Oriented and Achievement-Oriented Psychological Control. Journal of Personality, 78, 217-256. https://doi.org/10.1111/j.1467-6494.2009.00614.x

Sun, M., \& Lau, A. S. (2018). Exploring Cultural Differences in Expressive Suppression and Emotion Recognition. Journal of Cross-Cultural Psychology, 49, 664-672. https://doi.org/10.1177/0022022118763749

Tamis-LeMonda, C. S., Way, N., Hughes, D., Yoshikawa, H., Kalman, R. K., \& Niwa, E. Y. (2008). Parents' Goals for Children: The Dynamic Coexistence of Individualism and Collectivism in Cultures and Individuals: Topic Review. Social Development, 17, 183209.

UNICEF (2014). Children of the Recession: The Impact of the Economic Crisis on Child Well-Being in Rich Countries. Innocenti Report Card 12. https://www.unicef-irc.org/publications/pdf/rc12-eng-web.pdf

Van Doorn, M., Branje, S. J. T., \& Meeus, W. H. J. (2011). Developmental Changes in Parent-Adolescent Relationships: A Four-Wave Longitudinal Study. Journal of Youth and Adolescence, 40, 97-107. https://doi.org/10.1007/s10964-010-9516-7

Weitkamp, K., \& Seiffge-Krenke, I. (2018). The Association between Parental Rearing Dimensions and Adolescent Psychopathology: A Cross-Cultural Study. Journal of Youth and Adolescence, 48, 469-483. https://doi.org/10.1007/s10964-018-0928-0

Welti, C. (2002). Adolescents in Latin America: Facing the Future with Skepticism. In B. B. Brown, R. Larson, \& T. S. Saraswathi (Eds.), The World's Youth. Adolescents in Eight Regions of the Globe (pp. 276-306). Cambridge: Cambridge University Press. 
https://doi.org/10.1017/CBO9780511613814.010

Zaroff, C. M., Davis, J. M., Chio, P. H., \& Madhavan, D. (2012). Somatic Presentations of Distress in China. Australian and New Zealand Journal of Psychiatry, 46, 1053-1057. https://doi.org/10.1177/0004867412450077 